\title{
Psychiatric assessment and diversion schemes: problems associated with brief court reports
}

\author{
Clare Chambers and Jane Gill
}

\begin{abstract}
Mental health professionals are becoming increasingly involved with the criminal justice system through their work in psychiatric assessment and diversion schemes. Preparation of reports for the courts requires knowledge of the legal system. Those preparing such reports need specific training for this work.
\end{abstract}

Since the advent of the Read Review (Home Office, 1990), which recommended that ".. . . wherever possible mentally disordered offenders should receive care and treatment from health and social services rather than the criminal justice system", psychiatric assessment and diversion schemes for mentally disordered offenders have become increasingly widespread. The schemes are operated in a variety of ways, with the defendants being seen by diverse mental health workers, and at different stages during their passage through the criminal justice system. The premise is that such schemes result in benefit to mentally disordered defendants and that they assist the courts in making decisions about them. However, it is our contention that the reports may not be as valid as they appear, and that it is possible that they could adversely affect the judicial process.

Psychiatric reports for the courts are written evidence from expert witnesses. They should be factual, impartial and objective. Mr Justice Cazalet (Roberts, 1994) set out the following criteria which experts should use when preparing reports: they should provide a straightforward and not misleading opinion; they should be objective and not omit factors which do not support their opinion; and they should be properly researched. Furthermore, expert witnesses should seek only to assist the court in matters requiring expert knowledge and experience. Psychiatric reports written for the courts in relation to psychiatric assessment and diversion schemes should deal with the following specific issues: the presence and nature of any mental or physical disorder; the defendant's insight; his need for treatment and its most appropriate setting; the seriousness of his offending behav- iour; his propensity for dangerousness to others and/or himself; and his propensity for absconding.

Court reports outwith psychiatric assessment and diversion schemes are generally requested by the defence solicitors or by the prosecution. The usual procedure is for the relevant party to send a letter to the expert witness requesting that he see the defendant for the purpose of writing a report. The letter may detail the specific issues which should be examined and, if the written statements and records and tapes of interviews are not enclosed they may be requested. Thus, the expert witness may have knowledge, before he writes his report, of the statements of the defendant, complainant and witnesses, and of other relevant facts such as the defendant's previous convictions. The defendant may be interviewed at length, several times if necessary, and it may be possible to gather further information from medical records, psychological assessments, relatives of the defendant, etc. Consent is needed from the defendant for the preparation of the report. If the report is requested by the defendant's solicitor, he may choose not to disclose all or part of it if he feels that it would be prejudicial against the defendant. If the report is written for the prosecution, it has to be produced and disclosed to the defendant's solicitor.

The procedure for the preparation of a report for the courts by some psychiatric assessment and diversion schemes is rather different. One of the authors (C. C.) prepared reports and carried out research for the Leeds Magistrates' Mental Health Assessment and Diversion Scheme between May 1994 and March 1995. At that time defendants were referred to the scheme by bail information officers and police custody officers. The former are employed by the probation service and work under the supervision of probation officers, verifying information to assist the court in determining the outcome of a defendant's bail application. Referrals were also accepted from solicitors and the prosecution, but in practice this rarely occurred. The defendants were 
usually examined within 24 hours of arrest, prior to their first appearance before the magistrates. They were referred at about 8.30 am, after being interviewed by the bail information officers. The first court sitting started at $10.00 \mathrm{am}$. After examining the defendant, attempts were sometimes made to gain further information. The reports were then written and simultaneously presented to the defendant's solicitor, the prosecutor and the magistrate when the defendant appeared in court.

There are various problems which may arise from the above method of preparing a court report. First, the defendants are seen at a very early stage. They are likely to be very emotionally aroused, and to feel vulnerable and frightened. This may result in them appearing aggressive, paranoid or suicidal. It may also make them more suggestible and easily lead into making false statements or to agreeing to ideas that are put to them. The Police and Criminal Evidence Act Codes of Practice states that a person who is mentally disordered or mentally disabled must not be interviewed or asked to provide or sign a written statement in the absence of "the appropriate adult". The role of an appropriate adult is not just that of an observer: he has to advise the person being interviewed, observe whether the interview is being conducted properly and fairly, and facilitate communication for the person being interviewed. Police interviews are all, in addition, tape recorded, so verification can be made regarding what was actually said. Conversely, interviews for psychiatric assessment and diversion schemes are carried out in confidence. The assessor's conclusions are based, in the main, on the account given by the defendant, as this is the core of any psychiatric assessment. This account cannot be verified in the absence of verbatim records. Furthermore, if the defendant has been interviewed by the assessor using leading questions in a suggestible way, this could never be proved.

A second problem that can arise is in relation to corroboration of the defendant's statements, and the collection of further information about the defendant. The Home Office Circular 66/90 (1990) stated that mentally disordered persons should never be remanded to prison simply to receive medical treatment or assessment. However, it is important that defendants are adequately assessed prior to being released on bail into the community. From the personal experience of one of the authors (C. C.), it is not uncommon for defendants to lie, for example stating that they are receiving treatment from the local drug addiction unit when this is not the case. Apparent positive information such as this could facilitate release of the defendant on bail, when, if it were not the case, the magistrate might have reason to decide otherwise. The assessor might consider it appropriate to obtain corroborative information even in the absence of the prisoner's consent. This may, however, be difficult because the professionals contacted for the purpose may be reluctant to break confidentiality and face possible legal actions against them.

The issue of consent is the third problematic area. The defendant is entitled to refuse to be interviewed, or to refuse to allow the report to be prepared or presented. In this situation, a report may only be presented to the court if disclosure is justified in the public interest in order to prevent serious harm to the defendant or to the public. W. v. Egdell (1990, 1 ALL ER 835) is the leading case on this issue. The patient took action against the psychiatrist for breach of confidentiality, but the judge dismissed his claim on the grounds that the duty of confidentiality was, in this case, subordinate to the duty that the psychiatrist had to ensure that the authorities were fully informed about the patient's mental condition when making decisions concerning his future. Mental health assessors preparing reports for the court, in the context of a court diversion scheme, may have to make rapid decisions about whether or not to present a report to court against the wishes of the prisoner. Assessors have an ethical duty to inform the defendant about the limitation of confidentiality before the assessment takes place. If they consider revealing information against the wishes of the defendant, they should discuss the situation first with their colleagues, and it may also be appropriate for them to discuss it with their medical defence society.

A fourth area where problems may arise is in relation to the use which may be made of the report. The defence and prosecution have competing interests, and they sometimes have different perspectives to those of the court or any medical professional involved. This is of crucial importance. In one case a man was accused of an attempted robbery and of carrying an offensive weapon. The man was interviewed by the psychiatric assessment and diversion scheme assessor, who reported that the man had said that he always carried the weapon for fear of being attacked. The report was presented in court, and the defendant's solicitor objected to this statement, as the defendant had made no admission of possession of a weapon throughout lengthy police interviews during which the solicitor had been present. These interviews had been carried out in accordance with the Police and Criminal Evidence Act Codes of Practice, unlike the psychiatric assessment interview. From the point of view of the prosecution and the magistrate, however, the admission was of vital importance in determining the extent to which the defendant was at risk of further 
offending or of being a threat to the witnesses in the case. Assessors are thus faced with the dilemma of how to explain the reasoning behind the conclusions which they draw without disclosing information which may be highly prejudicial to the defendant. It is an area which is fraught with difficulty as, in general, neither the prosecution nor the defendant's solicitor has requested the report, so it can seem unclear as to whether either party can demand that part or all of the report be suppressed. In our opinion, it is best to act as if the report has been requested directly by the court, as the court has the overall responsibility for both public protection and the protection of vulnerable mentally disordered offenders. As Gudjonsson (1994) states, all relevant information that emerges from the assessment should be disclosed. Deleting salient parts at the request of the referring agent because they are not favourable seriously undermines the expert's objectivity and integrity, as well as possibly misleading the court. Since the court's duty to address issues of public protection may conflict with the defendant's own interests in the presentation of his case, the defendant should be asked to consent to the report being prepared on the understanding that anything that he says may be reported and that his solicitor may not be able to prevent this. He should be advised that he is not obliged to discuss the alledged offence, but that if he does the records made may be used in evidence at his trial.

In conclusion, the preparation of mental health reports for the purpose of a magistrates' courts assessment and diversion scheme is at least as complex and difficult as the preparation of the other reports for the courts. These reports are prepared by mental health workers from a variety of professionals including medicine, nursing and social work. Very little training, if any, is routinely given to any of these professionals regarding the preparation of court reports. In our opinion, such training is of especial importance for professionals who are expected to write impartial, accurate, factual and helpful reports for the courts in a limited space of time, with little access to corroborative information and in stressful situations. The training should include education about: the adversarial nature of the British criminal justice system, which produces the conflicting interests of the prosecution and the defence; the differing needs of the parties which may request that the report be prepared; consent; the purpose of the report; the issues with which it is appropriate for the report to deal; and the fundamental need to write clearly, concisely and unambiguously.

\section{References}

Gudjonsson, G. (1994) Confessions made to the expert witness: some professional issues. Journal of Forensic Psychiatry, 5, 237-257.

HOME OFFICE (1990) Provision for Mentally Disordered Offenders, Ctrcular 66/90. London: Home Office.

RoBERTS, R. E. (1994) The trials of an expert witness. Journal of the Royal Society of Medicine, 87, 628-631.

*Clare Chambers, Senior Registrar in Psychiatry, Leeds Community and Mental Health Services, Malham House, 25 Hyde Terrace, Leeds LS2 9LN; and Jane Gill, Deputy Clerk to the Justices, Leeds District Magistrates' Court, PO Box 97. Westgate, Leeds LS1 3JP

*Correspondence 